\title{
Protective effect of morin on myocardial ischemia-reperfusion injury in rats
}

\author{
SHUANG LIU $^{1}$, NAN WU ${ }^{2}$, JIAXIN MIAO ${ }^{1}$, ZIJUN HUANG ${ }^{1}$, XUYING LI $^{1}$, \\ PENGYU JIA ${ }^{1}$, YUXUAN GUO ${ }^{1}$ and DALIN JIA ${ }^{1}$ \\ ${ }^{1}$ Department of Cardiology and ${ }^{2}$ The Central Laboratory, The First Affiliated Hospital \\ of China Medical University, Shenyang, Liaoning 110001, P.R. China
}

Received February 7, 2018; Accepted June 22, 2018

DOI: $10.3892 /$ ijmm.2018.3743

\begin{abstract}
Morin, a natural flavonol, exhibits antioxidative, anti-inflammatory and anti-apoptotic effects in various pathological and physiological processes. However, whether morin exerts a protective effect on myocardial ischemia-reperfusion injury (MIRI) is unknown. The present study aimed to determine the effect of morin on MIRI in cultured cardiomyocytes and isolated rat hearts, and to additionally explore the underlying mechanism. The effect of morin on the viability, lactate dehydrogenase (LDH) activity and apoptosis of $\mathrm{H} 9 \mathrm{c} 2$ cardiomyocytes subjected to hypoxia/reoxygenation, and cardiac function and infarct size of rat hearts following ischemia/reperfusion in an animal model were measured. Furthermore, the mitochondrial permeability transition pore (MPTP) opening, mitochondrial membrane potential $(\Delta \Psi \mathrm{m})$, and the change in the expression levels of B-cell lymphoma 2 (Bcl2)-associated X protein (Bax), Bcl-2 and mitochondrial apoptosis-associated proteins following MPTP opening were also detected. The results indicated that morin treatment significantly increased cell viability, decreased LDH activity and cell apoptosis, improved the recovery of cardiac function and decreased the myocardial infarct size. Furthermore, morin treatment markedly inhibited MPTP opening, prevented the decrease of $\Delta \Psi \mathrm{m}$, and decreased the expression of cytochrome $c$, apoptotic protease activating factor-1, caspase- 9 , caspase- 3 and the Bax/Bcl-2 ratio. However, these beneficial effects were reversed by treatment with atractyloside, an MPTP opener. The present study demonstrated that morin may prevent MIRI by inhibiting MPTP opening and revealed the possible mechanism of the cardioprotection of morin and its acting target. It also provided an important theoretical basis
\end{abstract}

Correspondence to: Professor Dalin Jia, Department of Cardiology, The First Affiliated Hospital of China Medical University, 155 North Nanjing Street, Heping, Shenyang, Liaoning 110001, P.R. China E-mail: jd12001@126.com

Key words: myocardial ischemia-reperfusion injury, morin, atractyloside, mitochondrial permeability transition pore, apoptosis for the research on drug interventions for MIRI in clinical applications.

\section{Introduction}

Acute myocardial infarction (AMI) is one of the most severe fatal conditions worldwide (1). AMI is caused by the complete blockage of the coronary artery which can lead to serious complications following myocardial necrosis, including malignant ventricular arrhythmia, heart failure, rupture of the heart and even sudden cardiac death. Thus, AMI patients remain at a higher risk of long-term mortality following discharge from hospitals $(2,3)$. Restoration of the blood supply to the heart, termed reperfusion, is considered the most effective treatment for patients with AMI $(4,5)$. However, reperfusion itself may aggravate the extent of myocardial injury, which is termed myocardial ischemia-reperfusion injury (MIRI) (6). The manifestations of MIRI include myocardial stunning, severe fatal ventricular arrhy thmia, no reflow in coronary artery or even enlargement of myocardial infarct size $(4,7)$. Although several methods, including ischemic preconditioning, ischemic post-conditioning and remote ischemic preconditioning, have been demonstrated to alleviate MIRI (8-10), these procedures are limited in clinical practice due to medical ethics. Therefore, identification of a novel drug to prevent and mitigate MIRI that is more viable in clinical practice has become the focus of clinical studies.

The process of MIRI is complex and involves multiple mechanisms, including oxidative stress, inflammatory response and apoptosis (11-13). The mitochondrial membrane permeability transition pore (MPTP) is a transmembrane structure of mitochondria. MPTP has been identified as a key modulator of MIRI (14). Several studies have identified that MPTP remains closed during myocardial ischemia, but becomes open in the early stage of reperfusion (15). MPTP opening is usually induced by increased cytosolic and mitochondrial matrix $\mathrm{Ca}^{2+}$ levels, accumulation of reactive oxygen species (ROS) and oxidative stress (16-18). Blocking the opening of MPTP with its specific inhibitor (cyclosporin A) prior or subsequent to ischemia may attenuate MIRI in animals and humans $(19,20)$. Therefore, MPTP is an important therapeutic target for preventing MIRI. 
Morin, or 3,5,7,2',4'-pentahydroxyflavone, is a natural flavonol compound (21). Morin has multiple pharmacological effects, including antioxidative, anti-inflammatory and anti-apoptotic functions, scavenging of oxygen free radicals, inhibition of lipid peroxidation and improving the activities of various oxidases $(22,23)$. Furthermore, morin is able to scavenge reactive oxygen species (ROS) and decrease the level of ROS (23). Therefore, we hypothesized that morin may protect against MIRI by inhibiting the MPTP opening. Taken together, the aim of the present study was to determine the protective effect of morin on MIRI in cultured H9c2 cardiomyocytes and isolated rat hearts, and to additionally explore the critical role of MPTP in the cardioprotective effects of morin.

\section{Materials and methods}

Animals. A total of 135 healthy male SPF Wistar rats, weighing $300 \pm 20$ g, were purchased from Liaoning Changsheng Biotechnology Co., (Shenyang, China). The rats were housed in a quiet animal room maintained at $20-25^{\circ} \mathrm{C}$ with a relative humidity of $50-65 \%$. The rats were provided fresh food and water ad libitum and a 12-h light/dark cycle. The food was also purchased from Liaoning Changsheng Biotechnology Co., Ltd. All rats were treated and used according to the Guide for the Care and Use of Laboratory Animals (Federal Register Doc. 2011-11490; National Institutes of Health, Bethesda, MD, USA) (24). The experimental protocol was approved by the Institutional Ethics Committee of China Medical University.

Drugs. Morin (CAS, 480-16-0; purity, $\geq 98 \%$ ) and atractyloside (ATR; CAS, 102130-43-8, purity: $\geq 98 \%$ ) were purchased from Nantong Feiyu Biological Technology Co. Ltd. (Nantong, China). The 2,3,5-triphenyltetrazolium chloride (TTC) was purchased from Sigma-Aldrich; Merck KGaA (Darmstadt, Germany). Morin and ATR powder used in the animal experiments were dissolved in $10 \%$ polyethylene glycol 400 (PEG400; Beijing SolarBio Technology Co., Ltd., Beijing, China) and normal saline, respectively, to prepare solutions for intraperitoneal injections. Morin and ATR powders used in the cell experiments were dissolved in dimethyl sulfoxide (DMSO; Sigma-Aldrich; Merck KGaA).

Establishment of MIRImodel in isolated rathearts. Preparation of the heart tissue was performed as described previously (25). In brief, rats were anesthetized with intraperitoneal injection of pentobarbital sodium at a dose of $30 \mathrm{mg} / \mathrm{kg}$. Each rat heart was rapidly isolated following opening of the chest, and then placed into an iced heparinized $\mathrm{K}-\mathrm{H}$ solution $(\mathrm{NaCl} 0.15 \mathrm{~mol} / \mathrm{l}$, $\mathrm{KCl} 0.006 \mathrm{~mol} / \mathrm{l}, \mathrm{CaCl}_{2} 0.002 \mathrm{~mol} / \mathrm{l}, \mathrm{NaHCO}_{3} 0.002 \mathrm{~mol} / \mathrm{l}$ ), which was saturated with $100 \%$ oxygen. Subsequent to removal of the redundant connective tissue of the heart, each isolated rat heart was swiftly connected to the Langendorff apparatus through the aorta with a 7-0 surgical suture and continuously perfused using a K-H solution saturated with a mixed gas solution containing $95 \% \mathrm{O}_{2}$ and $5 \% \mathrm{CO}_{2}$ at the pressure of $75 \mathrm{mmHg}$ at $37^{\circ} \mathrm{C}$. All isolated rat hearts were perfused with the K-H solution using the perfusion apparatus and stabilized for 10 min prior to the induction of ischemia, and then subjected to global ischemia by stopping perfusion for $30 \mathrm{~min}$, followed by the induction of a $60 \mathrm{~min}$ reperfusion to induce MIRI.

Animal experimental protocol. The animal experiment consisted of two phases. In the first phase, 75 rats were randomly divided into 5 groups with 15 rats/group as follows: i) the ischemia-reperfusion group (IR); ii) the solvent group (vehicle): Rats were treated with $1.5 \mathrm{ml} \mathrm{10 \%} \mathrm{PEG400} \mathrm{by}$ intraperitoneal injection once/day for a total of 5 days prior to surgery; iii) the $10 \mathrm{mg} / \mathrm{kg}$ morin pretreatment group (morin 10 ): Rats were treated with $10 \mathrm{mg} / \mathrm{kg}$ morin by intraperitoneal injection once/day for a total of 5 days prior to surgery; iv) the $20 \mathrm{mg} / \mathrm{kg}$ morin pretreatment group (morin20): Rats were treated with $20 \mathrm{mg} / \mathrm{kg}$ morin by intraperitoneal injection as aforementioned for the morin 10 group; and v) the $40 \mathrm{mg} / \mathrm{kg}$ morin pretreatment group (morin40): Rats were treated with $40 \mathrm{mg} / \mathrm{kg}$ morin by intraperitoneal injection as aforementioned for the morin10 group.

Based on the results at the first phase, morin at a dose of $20 \mathrm{mg} / \mathrm{kg}$ was used to additionally explore the mechanism of action. Therefore, in the second phase, 60 rats were randomly divided into 4 groups with 15 rats per group, as follows: i) The IR group; ii) the vehicle group; iii) the morin20 group; and iv) the morin 20 combined with ATR group (morin20+ATR): Following treatment with $20 \mathrm{mg} / \mathrm{kg}$ morin the rats were additionally treated with ATR by intraperitoneal injection $30 \mathrm{~min}$ prior to surgery at a dose of $5 \mathrm{mg} / \mathrm{kg}$.

Cell culture. H9c2 cardiomyocytes (Shanghai Institutes for Biological Sciences, China, Chinese Academy for Sciences, Shanghai, China) were cultured in Low Glucose Dulbecco's Modified Eagle's Medium (Gibco; Thermo Fisher Scientific, Inc., Waltham, MA, USA) containing $10 \%$ fetal bovine serum (FBS; TBD, Tianjin, China) and 1\% penicillin/streptomycin (HyClone; GE Healthcare Life Sciences, Logan, UT, USA) under humid conditions in incubators with $5 \% \mathrm{CO}_{2}$ at $37^{\circ} \mathrm{C}$.

Cell experimental protocol. The H9c2 cells were subjected to hypoxia/reoxygenation to mimic the MIRI model in vitro. Specifically, cells were treated when the confluence of cells was $80-90 \%$. The culture medium was removed and changed to Earle's medium $\left(\mathrm{CaCl}_{2} 0.18 \mathrm{mmol} / \mathrm{l}, \mathrm{MgSO}_{4}, 7 \mathrm{H}_{2} \mathrm{O}\right.$ $0.08 \mathrm{mmol} / \mathrm{l}, \mathrm{KCl} 0.05 \mathrm{mmol} / \mathrm{l}, \mathrm{NaCl} 11.43 \mathrm{mmol} / \mathrm{l}, \mathrm{NaHCO}_{3}$ $2.62 \mathrm{mmol} / \mathrm{l}$ and $\mathrm{NaH}_{2} \mathrm{PO}_{4} 0.10 \mathrm{mmol} / \mathrm{l}$ ) without glucose and FBS, and cells were cultured in a tri-gas incubator with $90 \%$ $\mathrm{N}_{2}, 5 \% \mathrm{CO}_{2}$ and $5 \% \mathrm{O}_{2}$ at $37^{\circ} \mathrm{C}$ for $12 \mathrm{~h}$ to induce hypoxia. Subsequently, Earle's medium was removed, and the cells were cultured for $1 \mathrm{~h}$ with normal medium in incubators with $5 \%$ $\mathrm{CO}_{2}$ at $37^{\circ} \mathrm{C}$ to re-oxygenate the samples.

Similar to the aforementioned animal experimental protocol, cells were divided into six groups during the first phase as follows: i) The control group (control): Cardiomyocytes were cultured under normal conditions for $13 \mathrm{~h}$; ii) the hypoxia/reoxygenation group (HR): Cardiomyocytes were subjected to hypoxia for $12 \mathrm{~h}$ followed by reoxygenation for $1 \mathrm{~h}$; iii) the solvent group (vehicle): Cardiomyocytes were pretreated with $0.1 \%$ DMSO for $12 \mathrm{~h}$ followed by hypoxia/reoxygenation as described above for the HR group; iv) the $12.5 \mu \mathrm{M}$ morin pretreatment group (morin12.5): Cardiomyocytes were pretreated with morin at a dose of $12.5 \mu \mathrm{M}$ for $12 \mathrm{~h}$, followed 
by hypoxia/reoxygenation as described above for the HR group; v) the $25 \mu \mathrm{M}$ morin pretreatment group (morin25): Cardiomyocytes were pretreated with morin at a dose of $25 \mu \mathrm{M}$ for $12 \mathrm{~h}$, followed by hypoxia/reoxygenation as aforementioned for the HR group; and vi) the $50 \mu \mathrm{M}$ morin pretreatment group (morin50): Cardiomyocytes were pretreated with morin at a dose of $50 \mu \mathrm{M}$ for $12 \mathrm{~h}$ followed by hypoxia/reoxygenation as aforementioned for the HR group.

According to the result of the first phase, morin at a dose of $25 \mu \mathrm{M}$ was used to additionally explore the mechanism of action. Cells were subsequently divided into four groups in the second phase, as follows: i) The control group; ii) the HR group; iii) the morin 25 group; and iv) the $25 \mu \mathrm{M}$ morin combined with $20 \mu \mathrm{M}$ ATR pretreatment group (morin25+ATR): Cardiomyocytes were pretreated with morin at a dose of $25 \mu \mathrm{M}$ and ATR at a dose of $20 \mu \mathrm{M}$ for $12 \mathrm{~h}$ followed by hypoxia/reoxygenation as aforementioned for the HR group.

Cardiac function monitoring. Cardiac function parameters, including heart rate and coronary flow, were measured at $10 \mathrm{~min}$ of stabilization, and at 30 and $60 \mathrm{~min}$ following reperfusion.

Hematoxylin \& eosin (HE) staining. The hearts were removed from the perfusion apparatus at the end of reperfusion. The heart tissues were fixed in $4 \%$ paraformaldehyde at room temperature for $24 \sim 72 \mathrm{~h}$. Then, the tissues were washed with flowing water for $4 \mathrm{~h}$, and immersed in $70 \%$ ethanol for $2 \mathrm{~h}, 80 \%$ ethanol overnight, $90 \%$ ethanol for $2 \mathrm{~h}$, anhydrous ethanol I for $1 \mathrm{~h}$, and anhydrous ethanol II for $1 \mathrm{~h}$ at room temperature to be dehydrated. Following dehydration the tissues were paraffin embedded and the paraffin blocks cut into $5-\mu \mathrm{m}$-thick paraffin sections. The paraffin sections were immersed in xylene I for $15 \mathrm{~min}$, xylene II for $15 \mathrm{~min}$, absolute ethanol I for $5 \mathrm{~min}$, absolute ethanol II for $5 \mathrm{~min}, 95 \%$ ethanol for $2 \mathrm{~min}, 85 \%$ ethanol for $2 \mathrm{~min}, 75 \%$ ethanol for $2 \mathrm{~min}$, and distilled water for $2 \mathrm{~min}$ at room temperature to be de-waxed and rehydrated. They were then immersed in hematoxylin solution for $5 \mathrm{~min}, 1 \%$ hydrochloric acid alcohol for $3 \mathrm{sec}$, and eosin solution for $3 \mathrm{~min}$ at room temperature for staining. The pathological changes in heart tissues were observed under a light microscope and images were captured at magnification, $\mathrm{x} 400$.

Measurement of the infarct size. The myocardial infarct size was measured by TTC staining. The hearts were harvested as aforementioned, and the heart samples were incubated at $-80^{\circ} \mathrm{C}$ for $30 \mathrm{~min}$. The frozen hearts were cut into $1-2 \mathrm{~mm}$ thick sections from the apex to the bottom of the hearts and incubated in a $1 \% \mathrm{TTC}$ solution at $37^{\circ} \mathrm{C}$ for $30 \mathrm{~min}$. Subsequently, heart slices were washed with 1X PBS and fixed in $4 \%$ paraformaldehyde at room temperature overnight. Images of the stained slices were captured using a digital camera and analyzed using Image $\mathrm{J} 2 \mathrm{x}$ analysis software (National Institutes of Health). The severity of the myocardial infarction was indicated by the ratio of the infarct size to the total size.

Measurement of cell viability. Cell viability was determined by CCK-8 assay using the Cell Counting Kit- 8 (Dojindo Molecular Technologies, Kumamoto, Japan) according to the manufacturer's protocol. The absorbance value was detected at a wavelength of $450 \mathrm{~nm}$ by ultramicro microporous plate spectrophotometer (Biotek Instruments, Inc., Winooski, UT, USA).

Measurement of lactate dehydrogenase ( $L D H)$ activity. $\mathrm{LDH}$ released from cardiomyocytes into the culture medium was determined using the LDH assay kit (Nanjing Jiancheng Bioengineering Institute, Nanjing, China) according to the manufacturer's protocol. The absorbance value was detected at a wavelength of $450 \mathrm{~nm}$ by ultramicro microporous plate spectrophotometer (Biotek Instuments, Inc.).

Measurement of apoptosis. Myocardial apoptosis was detected by terminal deoxynucleotidyl transferase dUTP nick end labeling (TUNEL) assay using and In Situ Cell Death Detection kit (Roche Diagnostics, Indianapolis, IN, USA) according to the manufacturer's protocol. The apoptotic cells were observed under a light microscope and $\geq 3$ fields of view at lease were captured at x400 magnification. Image-Pro Plus version 6.0 (Media Cybernetics, Inc., Rockville, MD, USA) was used for cell counting, and SPSS version 17.0 (SPSS, Inc., Chicago, IL, USA) used for data analysis.

Cell apoptosis was determined by flow cytometry analysis (LSRFortessa, BD Biosciences, Franklin Lakes, NJ, USA) using the Annexin V-Fluorescein isothiocyanate (FITC)/Propidium Iodide (PI) kit (Nanjing KeyGen Biotech Co., Ltd., Nanjing, China) to label the cells according to the manufacturer's protocol. SPSS version 17.0 (SPSS, Inc.) was used for data analysis.

Sensitivity of MPTP to calcium. The mitochondria were isolated from the heart tissues using the Mitochondrial Extract kit (BestBio Co., Shanghai, China) according to the manufacturer's protocol. The sensitivity of MPTP to calcium was determined using the Purified Mitochondrial Membrane Pore Channel Colorimetric Assay kit (Shanghai Genmed Pharmaceutical Technology Co., Ltd., Shanghai, China) according to the manufacturer's protocol.

Measurement of mitochondrial membrane potential $(\Delta \Psi \mathrm{m})$. The change in $\Delta \Psi \mathrm{m}$ was determined using the Mitochondrial Membrane Potential Assay kit with 5,5',6,6'-Tetrachloro-1,1', 3,3'-tetraethyl-imidacarbocyanine iodide (JC-1; Beyotime Institute of Biotechnology, Haimen, China) according to the manufacturer's protocol. JC-1 is an ideal fluorescent probe widely used for the detection of $\Delta \Psi \mathrm{m}$. When $\Delta \Psi \mathrm{m}$ is high, JC-1 accumulates in the matrix of mitochondria and forms J-aggregates that produce red fluorescence. However, when $\Delta \Psi \mathrm{m}$ decreases, JC-1 cannot aggregate in the matrix of the mitochondria and maintains a monomer that produces green fluorescence. The fluorescence was detected under a fluorescence microscope and images were captured at x400 magnification. Image-Pro Plus version 6.0 (Media Cybernetics, Inc.) was used for cell counting.

Reverse transcription-quantitative polymerase chain reaction $(R T-q P C R)$. Total RNA was extracted from myocardium and cardiomyocytes using TRIzol ${ }^{\circledR}$ reagent (Life Technologies; Thermo Fisher Scientific, Inc.). RNA was transcribed into cDNA using PrimeScript RT reagent kit with gDNA Eraser 
(Takara Bio, Inc., Otsu Japan) according to the manufacturer's protocol. The RNA was heated at $37^{\circ} \mathrm{C}$ for $15 \mathrm{~min}$ and at $85^{\circ} \mathrm{C}$ for $5 \mathrm{sec}$, and then cooled at $4^{\circ} \mathrm{C}$ to obtain cDNA. SYBR Premix Ex Taq II (Takara Bio, Inc.) was used for qPCR amplification, according to the manufacturer's protocol. The cDNA was amplified under the following four segments: Segment 1: $95^{\circ} \mathrm{C}$ for $5 \mathrm{~min}$; segment 2: 8 cycles of $95^{\circ} \mathrm{C}$ for $30 \mathrm{sec}, 60^{\circ} \mathrm{C}$ for $45 \mathrm{sec}, 72^{\circ} \mathrm{C}$ for $20 \mathrm{sec}$; segment 3: 35 cycles of $95^{\circ} \mathrm{C}$ for $30 \mathrm{sec}$, $56^{\circ} \mathrm{C}$ for $45 \mathrm{sec}, 72^{\circ} \mathrm{C}$ for $20 \mathrm{sec}$; segment $4: 95^{\circ} \mathrm{C}$ for $1 \mathrm{~min}$, $55^{\circ} \mathrm{C}$ for $30 \mathrm{sec}, 95^{\circ} \mathrm{C}$ for $30 \mathrm{sec}$. All oligonucleotide primer pairs and the reference primers ( $\beta$-actin) were designed by Sangon Biotech Co., Ltd. (Shanghai, China) (Table I). Relative gene expression was analyzed using the $2^{\Delta \Delta \mathrm{Cq}}$ method (26).

Western blot analysis. The myocardium and cardiomyocytes were homogenized with radioimmunoprecipitation assay lysis buffer (Beyotime Institute of Biotechnology). Following $15 \mathrm{~min}$ of centrifugation of $13,000 \mathrm{x} \mathrm{g}$ at $4^{\circ} \mathrm{C}$, the supernatants containing proteins were collected. Protein concentrations were measured using the BCA protein concentration kit (Beyotime Institute of Biotechnology). Subsequently, $30 \mu \mathrm{g}$ protein was denatured at $100^{\circ} \mathrm{C}$ for $10 \mathrm{~min}$, and then SDS-PAGE (12\% separation gel and 5\% stacking gel) electrophoresis was performed for protein separation, and then the proteins were transferred to a polyvinylidene fluoride (PVDF) membrane. The PVDF membrane was blocked with $5 \%$ skim milk for $1 \mathrm{~h}$ at room temperature, and then incubated with specific antibodies, including anti-B-cell lymphoma 2 (Bcl-2)-associated X protein (Bax; cat. no. WL01637; 1:1,000; Shenyang Wan Biotechnology Co., Ltd., Shenyang, China), anti-Bcl-2 (cat. no. WL01556; 1:1,000; Shenyang Wan Biotechnology Co., Ltd.), anti-cytochrome $c$ (cat. no. ab90529; 1:1,000; Abcam, Cambridge, UK), anti-apoptotic protease activating factor-1 (APAF-1; cat. no. ab2001; 1:1,000; Abcam), anti-cleaved caspase-9 (cat. no. 40503-1; 1:1,000; Signalway Anitbody LLC, College Park, MD USA), anti-cleaved caspase-3 (cat. no. ab2302; 1:1,000; Abcam) and anti- $\beta$-actin (cat. no. TA-09; 1:1,000; Beijing Zhongshan Jinqiao Biotechnology Co., Ltd., Beijing, China), at $4^{\circ} \mathrm{C}$ overnight. The following day, the PVDF membrane was incubated with horseradish peroxidase labeled goat anti-rabbit immunoglobulin G (cat. no. E030120-01; 1:4,000; EarthOx Life Sciences, Millbrae, CA, USA) or goat anti-mouse immunoglobulin G (cat. no. E030110-01; 1:4,000; EarthOx Life Sciences) at room temperature for $30 \mathrm{~min}$. Detection of protein bands was performed using an enhanced chemiluminescence for western blotting kit (Beyotime Institute of Biotechnology) according to the manufacturer's protocol. Relative densitometry was calculated using Image J2x analysis software (National Institutes of Health).

Statistical analysis. All data were presented as the mean \pm standard deviation and analyzed using SPSS software version 17.0 (SPSS, Inc., Chicago, IL, USA). Differences among $\geq$ three groups were firstly evaluated using one-way analysis of variance, and if the differences were significant, multiple comparison analysis was performed using Fisher's Least Significant Difference test. Differences between two groups were evaluated using independent sample t-test. $\mathrm{P}<0.05$ were considered to indicate a statistically significant difference.
Table I. Primer sequences in the present study.

Gene

Primer sequences $\left(5^{\prime}-3^{\prime}\right)$

Bax forward

Bax reverse

Bcl-2 forward

Bcl-2 reverse

Cytochrome $c$ forward

Cytochrome $c$ reverse

APAF-1 forward

APAF-1 reverse

Caspase-9 forward

Caspase- 9 reverse

Caspase- 3 forward

Caspase- 3 reverse

GGCGATGAACTGGACAACAA
CAGTTGAAGTTGCCGTCTGC
CACGGTGGTGGAGGAACTCT
TCCACAGAGCGATGTTGTCC
AGGGTGTCGCCTCAAACCTA
ACTGAAGCACGGGTGAGTCT
CAAGGACACAGACGGTGGAA
TGAATCGCACTGACCAGCTT
CAGGTGGAGGTCAGGTGTGA
TCCGTGAGAGAGGATGACCA
CCATCCTTCAGTGGTGGACA
TTGAGGCTGCTGCATAATCG

Bcl-2, B-cell lymphoma 2; Bax, Bcl-2-associated X protein; APAF-1, apoptotic protease activating factor-1.

\section{Results}

Effect of morin on cardiac function. No difference was observed in the heart rate across all the groups (Fig. 1A). Coronary circulation at 30 and $60 \mathrm{~min}$ of reperfusion in the morin 10 and morin 20 groups was significantly increased compared with the IR group (Fig. 1B).

Effect of morin on myocardial damage. The results of the HE staining indicated that myocardial damage was ameliorated following treatment with morin at different doses, as evidenced by less vacuolation in cytoplasm and a decreased number of cells exhibiting nuclear condensation, dissolution and fragmentation compared with the IR group. Compared with the morin10 group, fewer instances of severe myocardial damage were observed in the morin20 group (Fig. 2A). In addition, the myocardial infarct sizes following treatment with morin at different doses were significantly decreased compared with the IR group (Fig. 2B). Although there was no significant difference in myocardial infarct size between morin 20 and morin10 groups, it was identified visually that the extent of myocardial damage indicated in morin 20 group was less compared with that in morin 10 group through the result of $\mathrm{HE}$ staining. Therefore, the dose of $20 \mathrm{mg} / \mathrm{kg}$ was selected for the additional animal experiments.

The damage of cardiomyocytes caused by hypoxia/reoxygenation was evaluated by determining cell viability and LDH activity. The results demonstrated that cell viability was significantly increased and LDH activity was markedly decreased in different morin treatment groups (morin12.5, morin25 and morin50) compared with those in the HR group. However, there was no difference in cell viability and LDH activity among groups treated with different doses of morin (Fig. 2C and D). Although different doses of morin treatment groups exhibited no statistical difference in cell viability, the cell viability in morin $25 \mu \mathrm{M}$ group was increased by almost $10 \%$ compared with that in morin $12.5 \mu \mathrm{M}$ group 

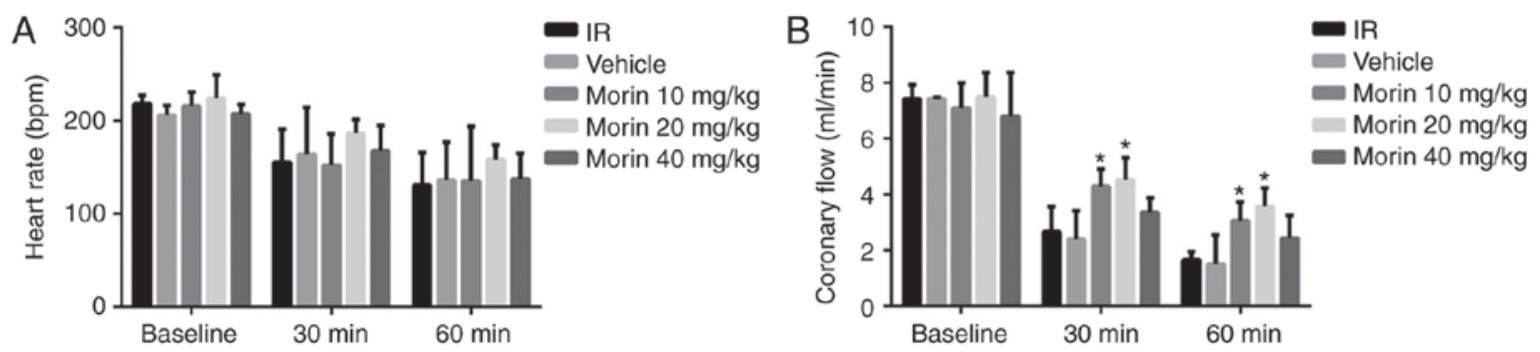

Figure 1. Cardiac function prior to and during reperfusion. (A) Heart rate. (B) Coronary circulation. Values are presented as the mean \pm standard deviation; $\mathrm{n}=3-15 ;{ }^{*} \mathrm{P}<0.05$ vs. the IR group. IR, ischemia/reperfusion.
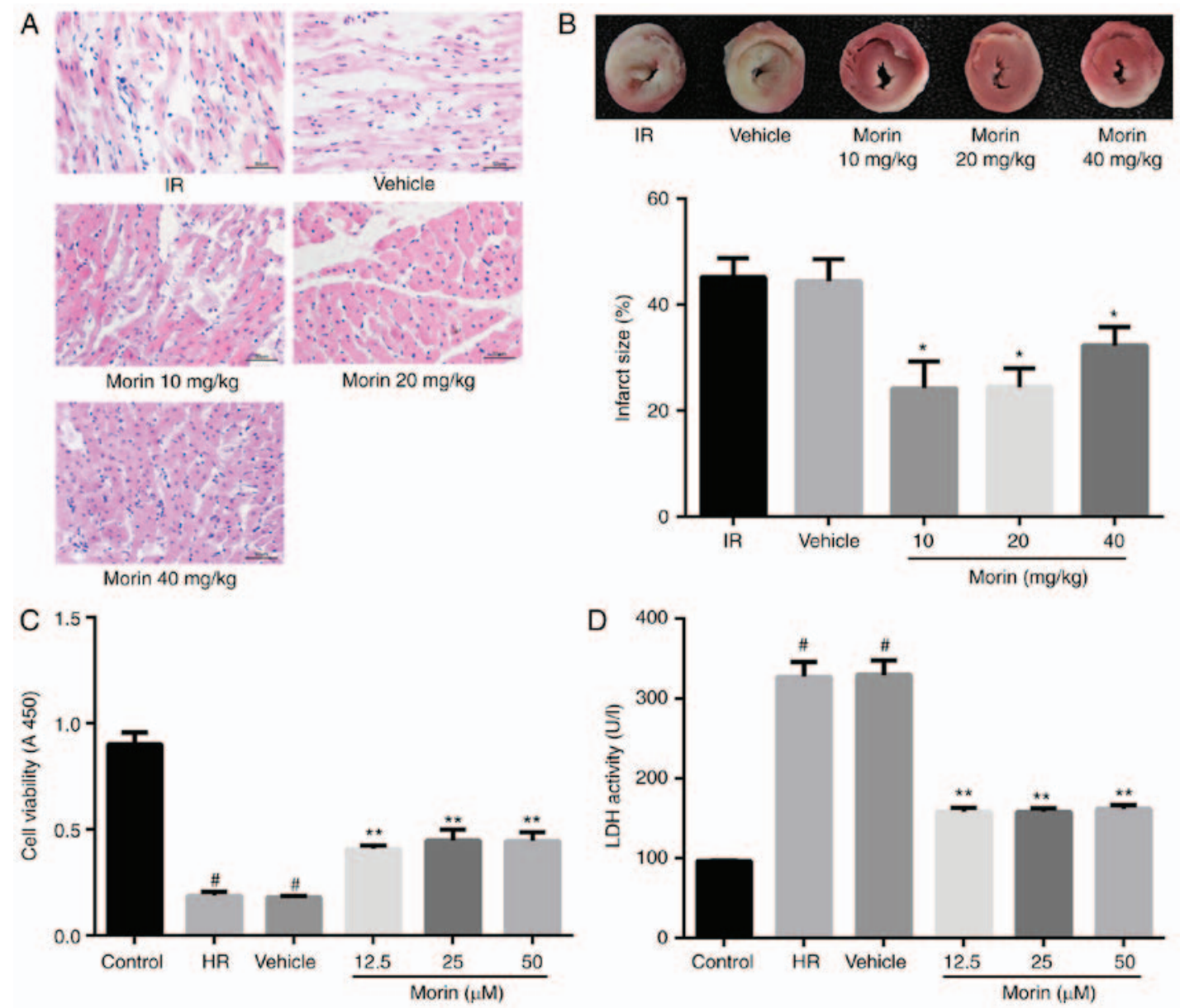

Figure 2. Protective effect of morin on myocardial ischemia-reperfusion injury in vitro and in vivo. (A) Photomicrographs were captured at magnification, x400. (B) Results of myocardial 2, 3,5-triphenyltetrazolium chloride staining and the percentage infarct size. The non-infarction areas were stained red or pink, whereas the infarction areas were white or gray. (C) Cell viability following hypoxia/reoxygenation. (D) Cell lactate dehydrogenase activity. Values are presented as the mean \pm standard deviation; $n=3-6$; ${ }^{*} \mathrm{P}<0.01$ vs. the IR group; ${ }^{*} \mathrm{P}<0.01$ vs. the control group; and ${ }^{* * *} \mathrm{P}<0.01$ vs. the HR group. IR, ischemia-reperfusion; HR, hypoxia/reoxygenation.

$(0.449 \pm 0.052$ vs. $0.409 \pm 0.017 ; \mathrm{P}=0.213)$. Considering that the sample size was relatively small $(n=3)$, we hypothesized that the statistical difference between these two groups may be observed if the sample size became larger. Therefore, the dose of $25 \mu \mathrm{M}$ was selected for additional cell experimentation.

Effect of morin on the alterations in MPTP opening and $\Delta \Psi m$. Calcium may induce MPTP opening (16). The sensitivity of mitochondria to calcium is a marker for MPTP opening (27). The results indicated that the sensitivity of mitochondria to calcium was significantly attenuated in the morin treatment group compared with the IR group, suggesting that morin inhibited the extent of MPTP opening (Fig. 3A and B). In addition, the results of $\Delta \Psi \mathrm{m}$ assay indicated that in the cardiomyocytes, the red fluorescence intensity was increased and green fluorescence intensity was decreased in the morin treatment group compared with the HR group, indicating that morin significantly inhibited the decrease of the $\Delta \Psi \mathrm{m}$ induced by hypoxia/reoxygenation (Fig. 3C).

Effect of morin on the expression levels of Bax and Bcl-2. Morin treatment significantly downregulated the mRNA 

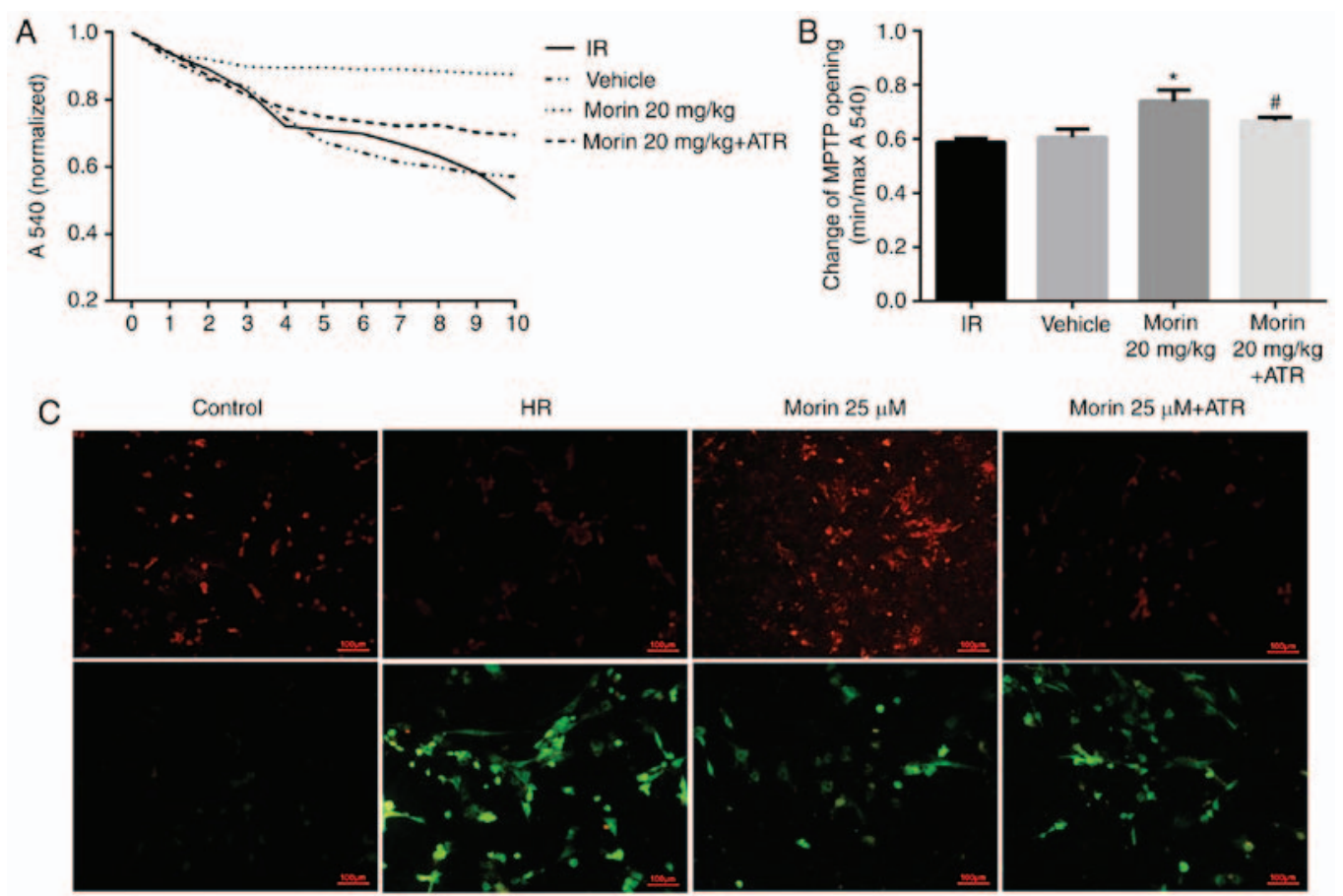

Morin $25 \mu \mathrm{M}+\mathrm{ATR}$
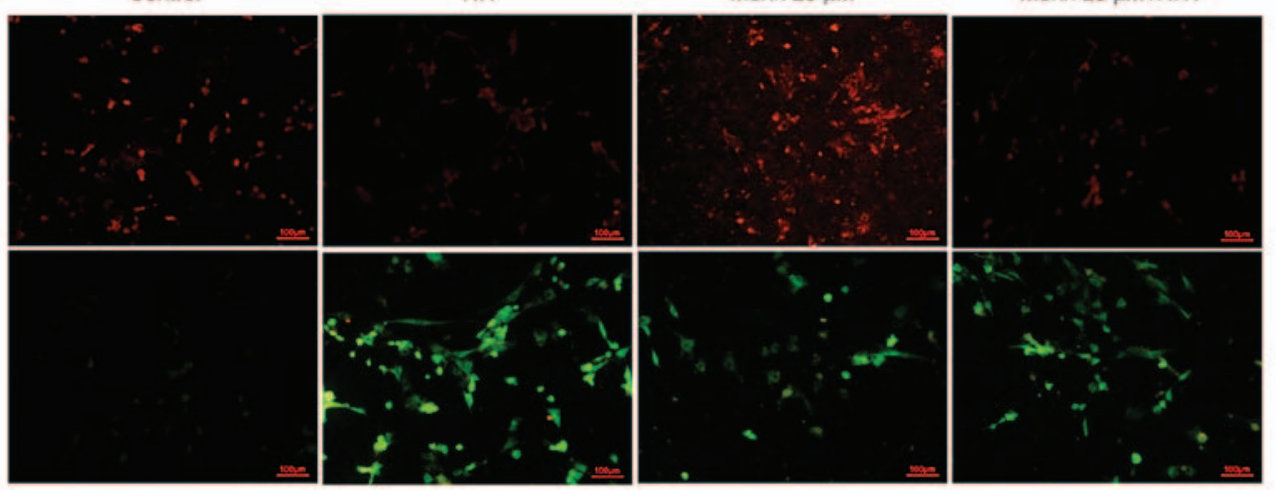

Figure 3. Changes in mitochondrial function. (A) Sensitivity of MPTP opening to calcium. (B) Alterations in MPTP opening. (C) Alterations in mitochondrial membrane potential. The presence of red fluorescence indicated normal $\Delta \Psi \mathrm{m}$ and state of the cells. The green fluorescence indicated that the $\Delta \Psi \mathrm{m}$ decreased, and the cells were most likely to be in the early stage of apoptosis. Values are presented as the mean \pm standard deviation; $n=3$; ${ }^{*} \mathrm{P}<0.01$ vs. the IR group; ${ }^{\text {"}} \mathrm{P}<0.05$ vs. the morin 20 group. MPTP, mitochondrial permeability transition pore; IR, ischemia-reperfusion; HR, hypoxia/reoxygenation; ATR, atractyloside; $\Delta \Psi \mathrm{m}$, mitochondrial membrane potential.

A
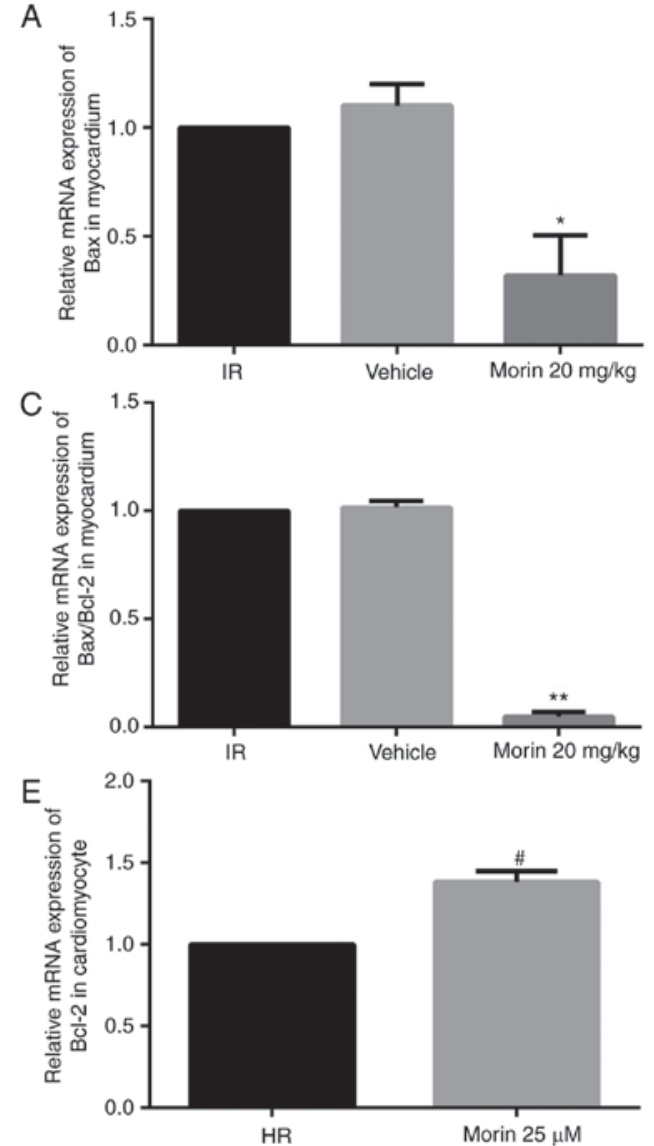

B
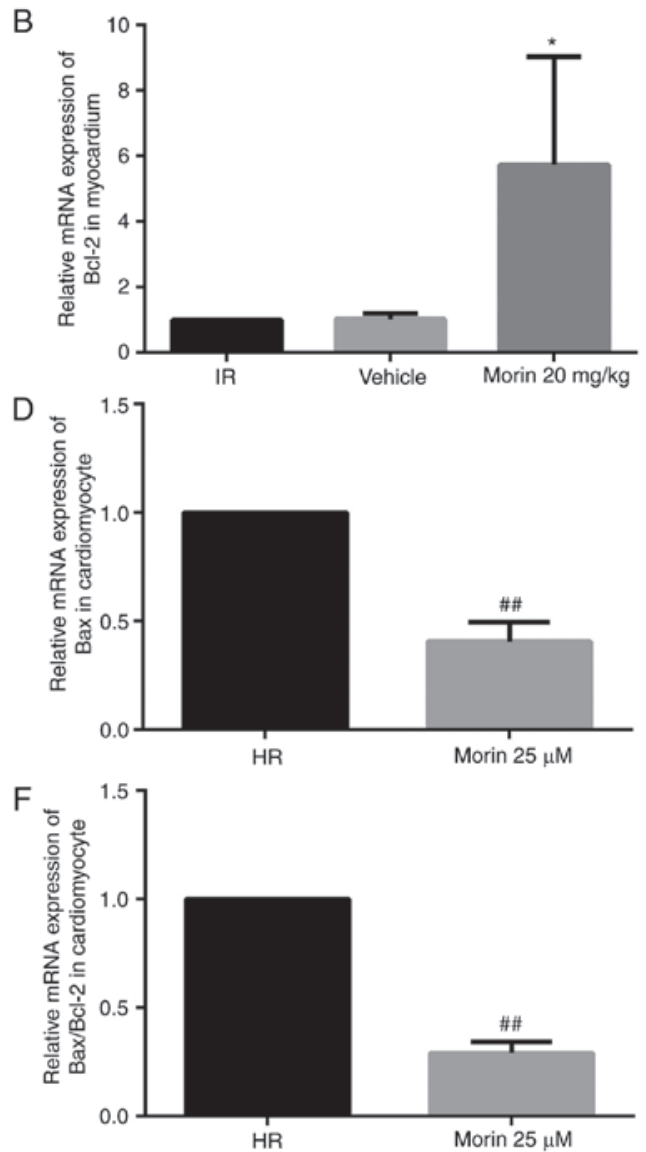

Figure 4. Relative mRNA expression levels of Bax and Bcl2, and the Bax/Bcl-2 ratio. (A) Relative mRNA expression level of Bax in the heart tissue. (B) Relative mRNA expression level of Bcl-2 in the heart tissue. (C) Relative Bax/Bcl2 mRNA ratio in the heart tissue. (D) Relative mRNA expression level of Bax in cardiomyocytes. (E) Relative mRNA expression level of Bcl-2 in cardiomyocytes. (F) Relative Bax/Bcl-2 mRNA ratio in cardiomyocytes. Values are presented as the mean \pm standard deviation; $n=3 ;{ }^{*} \mathrm{P}<0.05$ vs. the IR group; ${ }^{* *} \mathrm{P}<0.01$ vs. the IR group; ${ }^{*} \mathrm{P}<0.05$ vs. the HR group; ${ }^{\# \prime} \mathrm{P}<0.01$ vs. the HR group. IR, ischemia-reperfusion; HR, hypoxia/reoxygenation; Bcl-2, B-cell lymphoma 2; Bax, Bcl-2-associated X protein. 

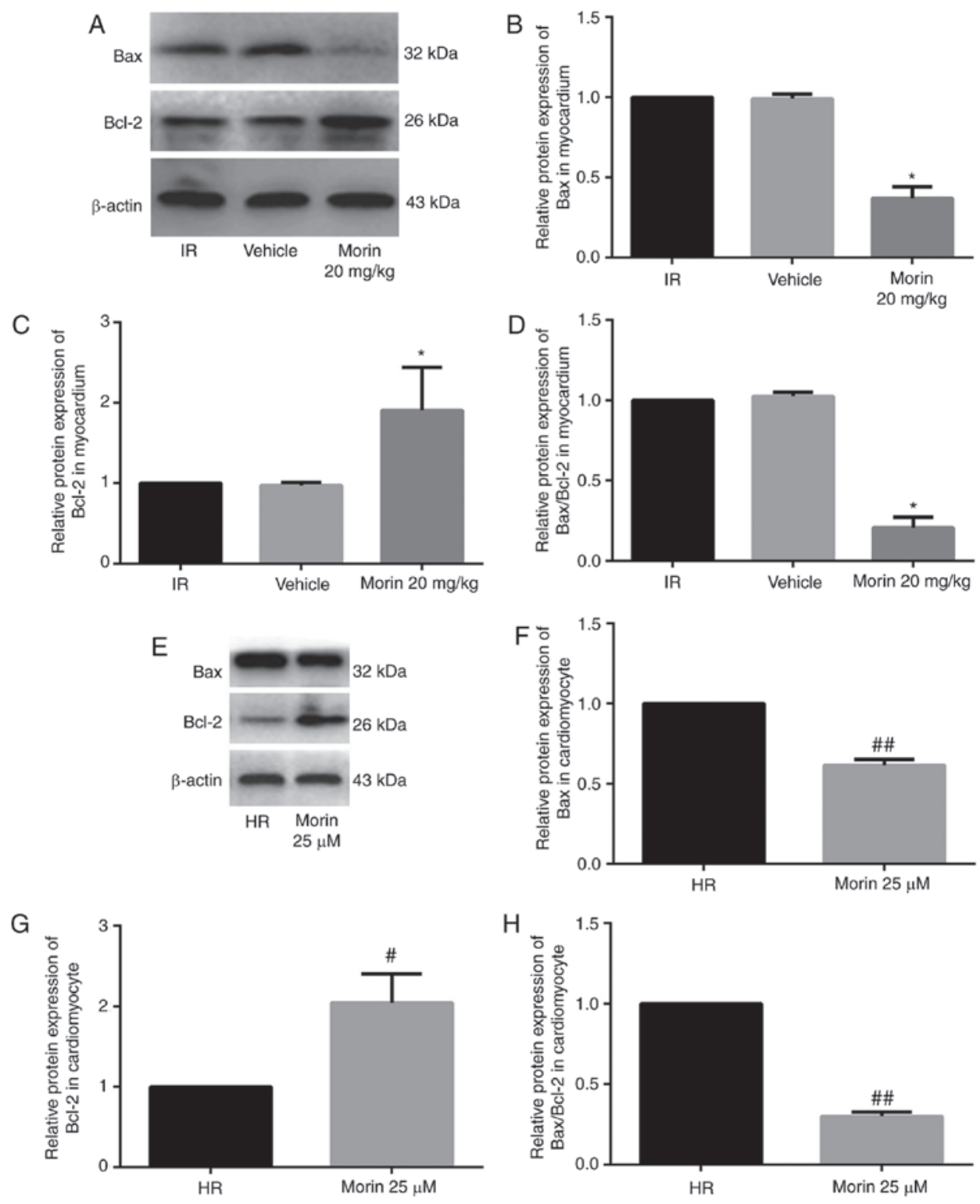

Figure 5. Relative protein expression levels of Bax and Bcl-2, and the Bax/Bcl-2 ratio. (A) Protein expression levels of Bax and Bcl-2 in the heart tissue detected by western blot analysis. (B) Relative protein expression level of Bax in the heart tissue. (C) Relative protein expression level of Bcl-2 in the heart tissue; (D) Relative Bax/Bcl-2 protein ratio in the heart tissue; (E) Protein expression levels of Bax and Bcl-2 in cardiomyocytes detected by western blot analysis (F) Relative protein expression level of Bax in cardiomyocytes. (G) Relative protein expression level of Bcl-2 in cardiomyocytes. (H) Relative Bax/Bcl-2 protein ratio in cardiomyocytes. Values are presented as the mean \pm standard deviation; $\mathrm{n}=3-6 ;{ }^{*} \mathrm{P}<0.01$ vs. the IR group; ${ }^{\#} \mathrm{P}<0.05$ vs. the $\mathrm{HR}$ group; ${ }^{\# \#} \mathrm{P}<0.01$ vs. the HR group. IR, ischemia-reperfusion; HR, hypoxia/reoxygenation; Bcl-2, B-cell lymphoma 2; Bax, Bcl-2-associated X protein.

expression of Bax, upregulated the mRNA expression of Bcl-2 and decreased the Bax/Bcl-2 ratio in the myocardium and in cardiomyocytes (Fig. 4). Consistent with the changes in mRNA expression levels, morin treatment also markedly downregulated the protein expression of Bax, upregulated the protein expression of $\mathrm{Bcl}-2$ and decreased the $\mathrm{Bax} / \mathrm{Bcl}-2$ ratio in the myocardium and in cardiomyocytes (Fig. 5).

Effect of morin on the mitochondrial apoptotic pathway and apoptosis. MPTP opening may activate the mitochondrial apoptotic pathway and induce apoptosis (15). Therefore, the present study explored the effect of morin on the apoptotic rate and on the expression of mitochondrial apoptosis-associated proteins. The results indicated that morin significantly decreased the mRNA and protein expression of cytochrome $c$,
APAF-1, caspase- 9 and caspase- 3 in the myocardium and in cardiomyocytes (Figs. 6 and 7). In addition, morin also significantly decreased the apoptotic rate of treated cells compared with the HR cells (Fig. 8).

ATR abrogated the protective effects of morin. To additionally confirm whether morin prevented MIRI through inhibition of MPTP opening, the effect of ATR, a known MPTP opener, on the protective effect of morin was examined. As expected, the inhibitory effects of morin on MPTP opening (Fig. 3A and B), the decrease of $\Delta \Psi \mathrm{m}$ (Fig. $3 \mathrm{C}$ ), the expression of mitochondrial apoptosis-associated proteins (Figs. 6 and 7) and apoptosis were reversed by ATR (Fig. 8). In addition, it was observed that myocardial infarct size was increased, cell viability was decreased and LDH activity was increased in the 
A

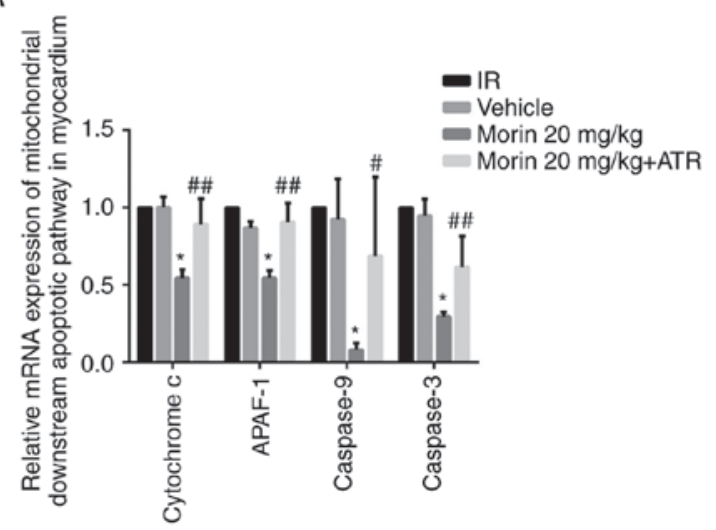

B

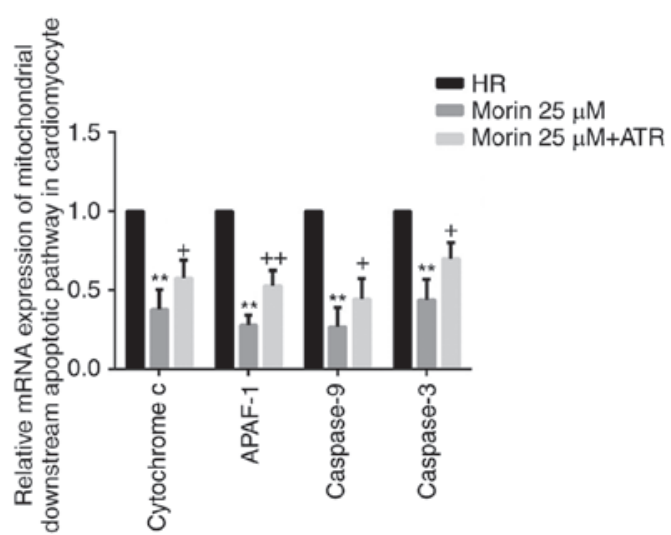

Figure 6. Relative mRNA expression levels of downstream genes of the mitochondrial apoptotic pathway. (A) Relative mRNA expression levels of cytochrome $c$, APAF-1, caspase-9 and caspase-3 in the heart tissue; (B) Relative mRNA expression levels of cytochrome $c$, APAF-1, caspase-9 and caspase-3 in cardiomyocytes. Values are presented as the mean \pm standard deviation; $n=3-5 ;{ }^{~} \mathrm{P}<0.01$ vs. the IR group; ${ }^{\# P}<0.05$ vs. the morin 20 group; ${ }^{\# \#} \mathrm{P}<0.01$ vs. the morin 20 group; ${ }^{* *} \mathrm{P}<0.01$ vs. the HR group; ${ }^{+} \mathrm{P}<0.05$ vs. the morin 25 group; ${ }^{++} \mathrm{P}<0.01$ vs. the morin 25 group. APAF-1, apoptotic protease activating factor-1; IR, ischemia-reperfusion; HR, hypoxia/reoxygenation.

A

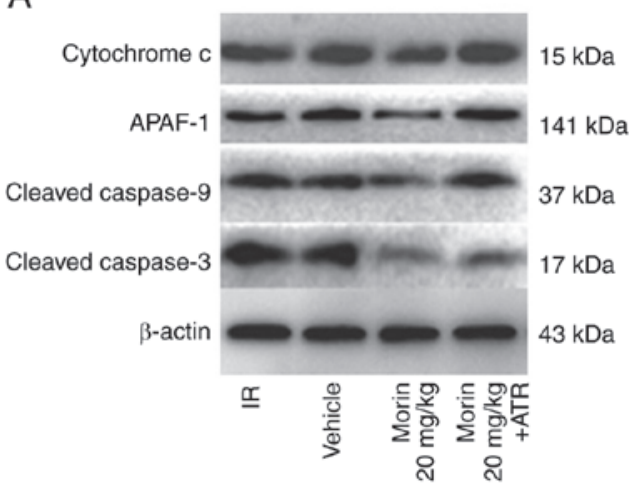

C

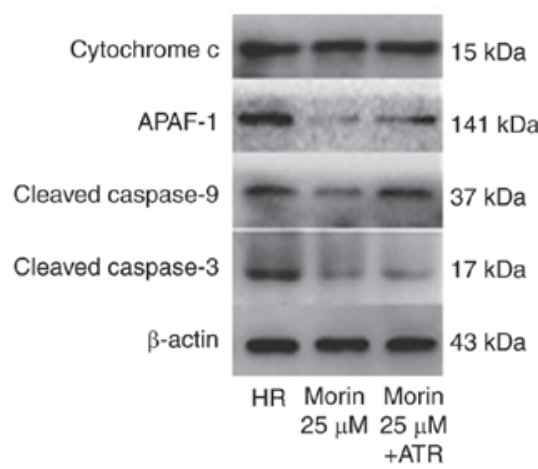

B

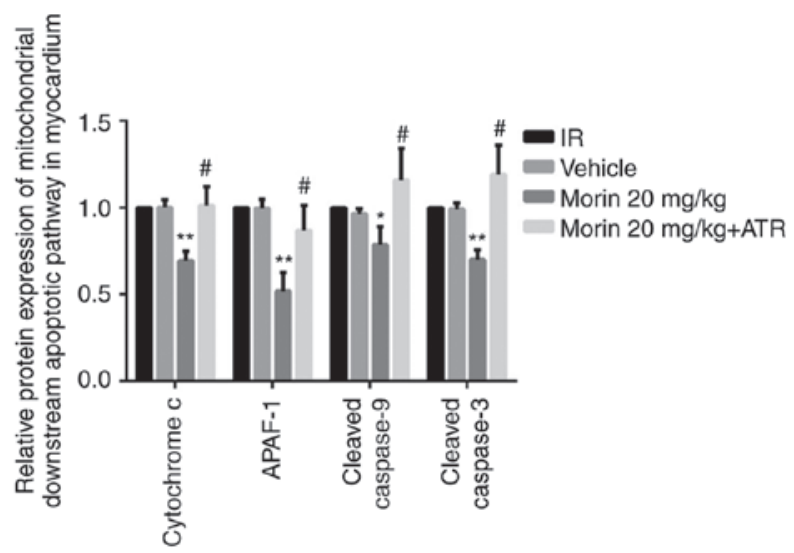

\section{D}

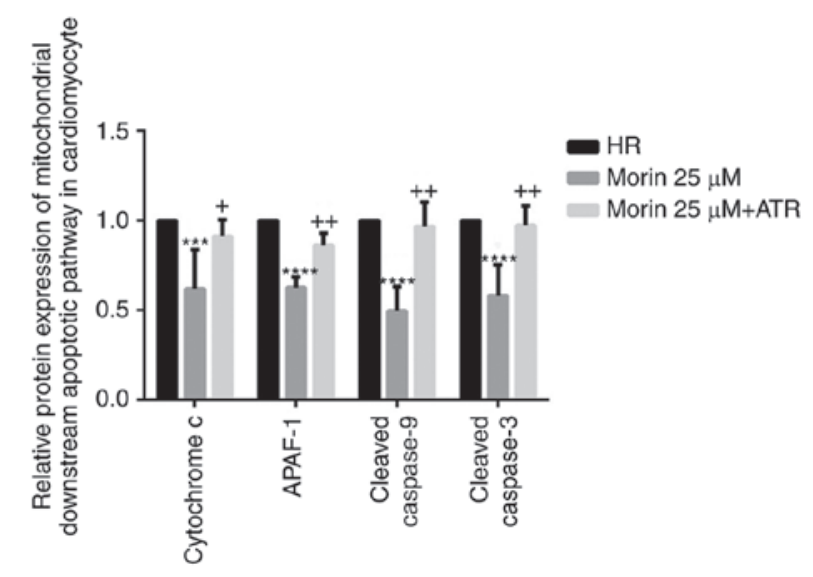

Figure 7. Relative protein expression levels of downstream genes of the mitochondrial apoptotic pathway. (A) Protein expression levels of cytochrome $c$, APAF-1, cleaved caspase-9 and cleaved caspase-3 in the heart tissue detected by western blot analysis. (B) Relative protein expression levels of cytochrome $c$, APAF-1, cleaved caspase-9 and cleaved caspase-3 in the heart tissue. (C) Protein expression levels of cytochrome $c$, APAF-1, cleaved caspase- 9 and cleaved caspase-3 in cardiomyocytes detected by western blot analysis. (D) Relative protein expression levels of cytochrome $c$, APAF-1, cleaved caspase-9 and cleaved caspase -3 in cardiomyocytes. Values are presented as the mean \pm standard deviation; $n=3-5 ;{ }^{*} \mathrm{P}<0.05$ vs. the IR group; ${ }^{* *} \mathrm{P}<0.01$ vs. the IR group; ${ }^{*} \mathrm{P}<0.01$ vs. the morin 20 group; ${ }^{* * *} \mathrm{P}<0.05$ vs. the HR group; ${ }^{* * * * *} \mathrm{P}<0.01$ vs. the HR group; ${ }^{+} \mathrm{P}<0.05$ vs. the morin 25 group; ${ }^{++} \mathrm{P}<0.01$ vs. the morin 25 group. APAF-1, apoptotic protease activating factor-1; IR, ischemia-reperfusion; HR, hypoxia/reoxygenation.

morin combined with ATR pretreatment groups as compared with the morin pretreatment groups (Fig. 9). Considering that previous studies had demonstrated that ATR at a dose of $5 \mathrm{mg} / \mathrm{kg}$ does not aggravate myocardial IR injury $(28,29)$, 
A
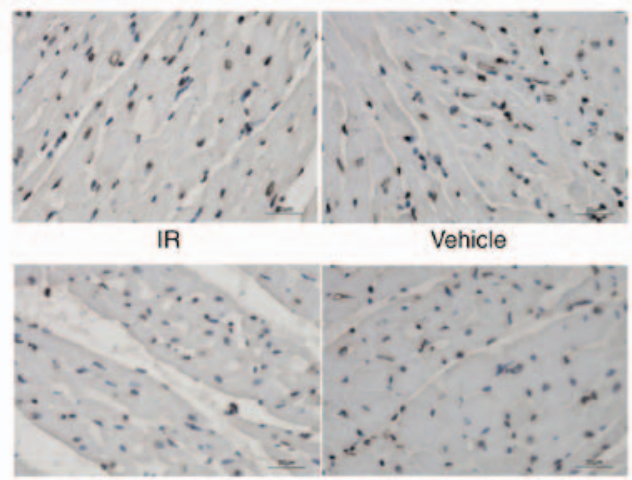

Morin $20 \mathrm{mg} / \mathrm{kg}$
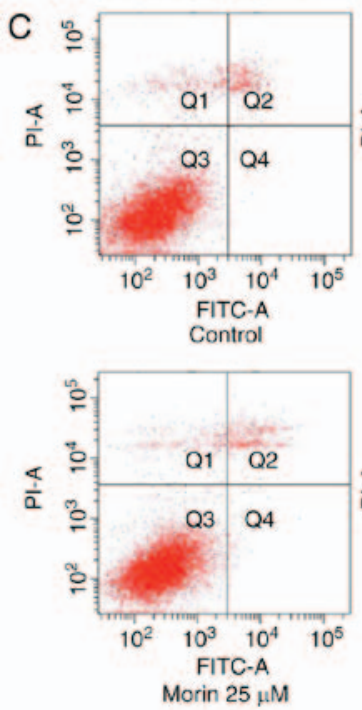

Morin $20 \mathrm{mg} / \mathrm{kg}+$ ATR
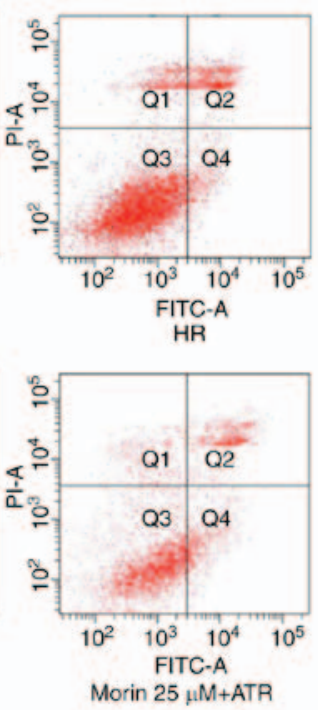

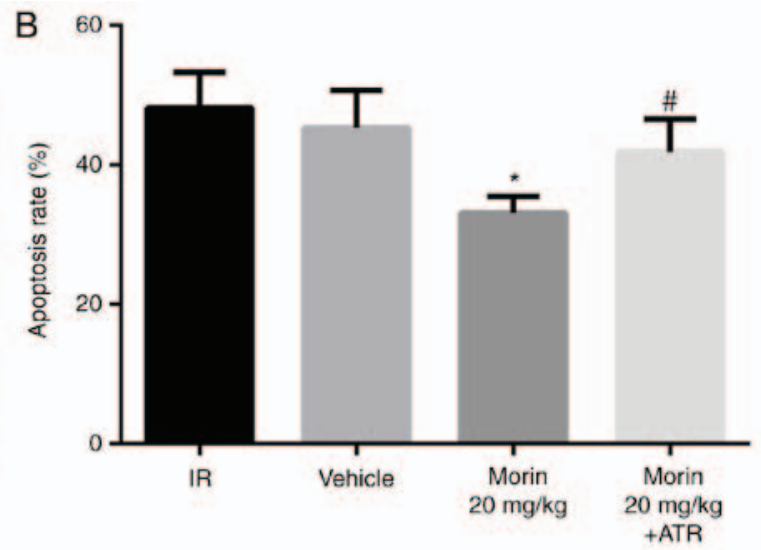

D

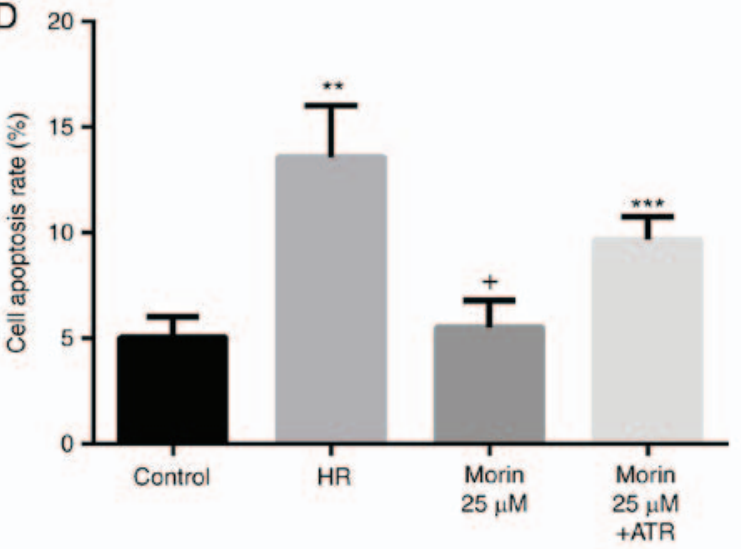

Figure 8. Apoptosis following myocardial infarction. (A) Photomicrographs were captured at magnification, x400. Apoptotic cardiomyocyte nuclear regions were stained brown, whereas terminal deoxynucleotidyl transferase dUTP nick end labeling-negative nuclear regions appeared blue. (B) The percentage apoptosis rate. (C) Cell apoptosis detected by flow cytometry. (D) Cell apoptosis rate. Values are presented as the mean \pm standard deviation; $\mathrm{n}=3-8$; ${ }^{\mathrm{P}}<0.01 \mathrm{vs}$. the IR group; ${ }^{*} \mathrm{P}<0.01$ vs. the morin 20 group; ${ }^{* *} \mathrm{P}<0.01$ vs. the control group; ${ }^{+} \mathrm{P}<0.01$ vs. the HR group; ${ }^{* * *} \mathrm{P}<0.05 \mathrm{vs}$. the morin 25 group. IR, ischemia-reperfusion; HR, hypoxia/reoxygenation; ATR, atractyloside; FITC, fluorescein isothiocyanate; PI, propidium iodide.

these results suggest that the protective effects of morin were abrogated by induction of MPTP opening using ATR.

\section{Discussion}

In the present study, it was identified that morin treatment prior to ischemia markedly alleviated the extent of MIRI, as evidenced by the increased cell viability, decreased LDH activity and cell apoptosis, the improved recovery of cardiac function and the reduction of myocardial infarct size observed. Although Al-Numair et al (30) previously demonstrated that morin exhibited an antioxidative activity in an isoproterenol-induced model of myocardial infarction, they did not provide direct evidence of the protective effect of morin on myocardial ischemia injury. To the best of our knowledge, this is the first study to describe the protective effect of morin on MIRI in detail. Therefore, morin seems to be a promising compound that may be used for preventing MIRI. A number of drugs and chemical compounds, including rosuvastatin (31), tauroursodeoxycholic acid (32), tilianin (33) and phosphodiesterases (34), have been demonstrated to prevent MIRI by inhibition of MPTP opening. Woodman et al (35) confirmed that 3',4'-dihydroxyflavonol, a flavonoid compound, may inhibit MPTP opening and preserve mitochondrial function. In the present study, the results indicated that morin decreased the sensitivity of MPTP to calcium, which is a marker of MPTP opening, therefore suggesting that morin inhibited the opening of MPTP. To the best of the authors' knowledge, this is a novel result within this field of study. The irreversible opening of MPTP causes the loss of $\Delta \Psi \mathrm{m}$ (36), release of cytochrome $c$ to the cytoplasm and activation of mitochondrial apoptosis-associated proteins, including APAF-1, caspase-9 and caspase-3, subsequently resulting in apoptosis induction $(37,38)$. As expected, the present study also identified that morin prevented the loss and preserved the stability of $\Delta \Psi \mathrm{m}$. In addition, the expression levels of cytochrome $c$, APAF-1, cleaved caspase- 9 and cleaved caspase-3 were significantly decreased by morin treatment. Similar to the results of the present study, Chen et al (22) identified that morin decreased the expression of caspase 3 in focal cerebral ischemic rats. In addition, the present study demonstrated that the beneficial effects of morin on MIRI were reversed by an MPTP opener (ATR), therefore providing additional evidence of morin-mediated inhibition of MPTP opening (39). Taken together, we hypothesize that morin may prevent MIRI by inhibiting MPTP opening. 
A

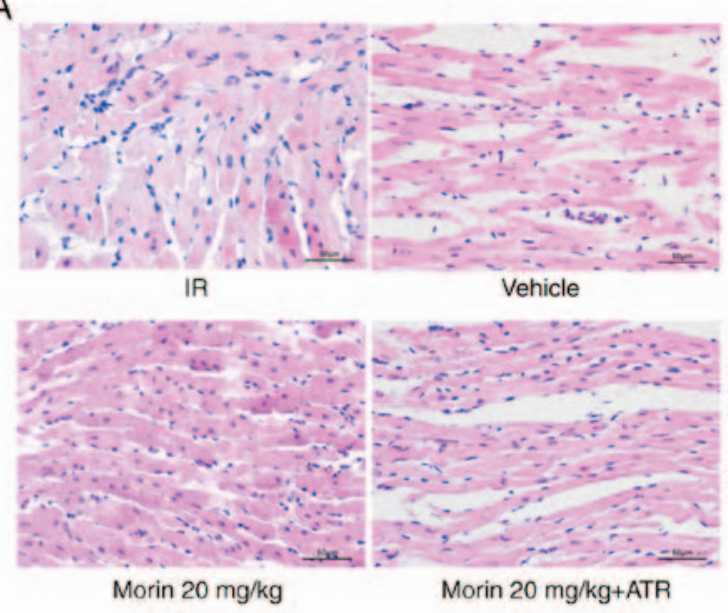

B
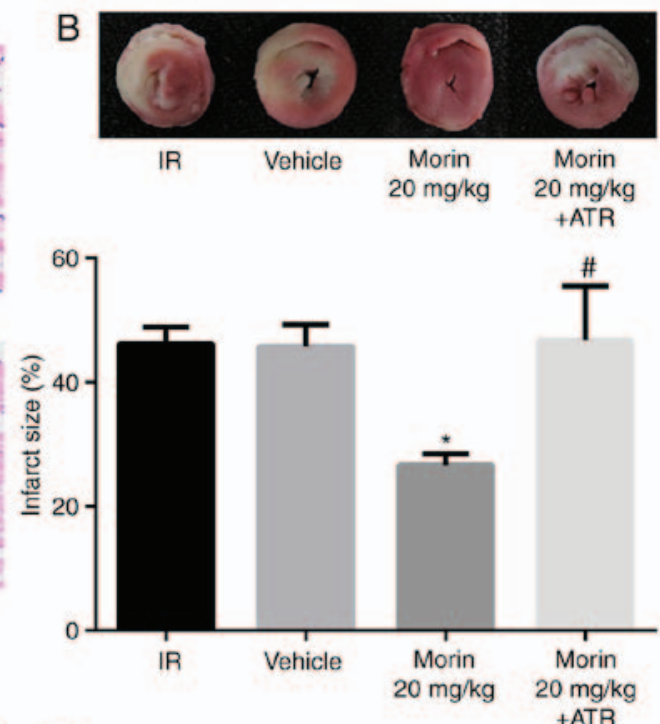
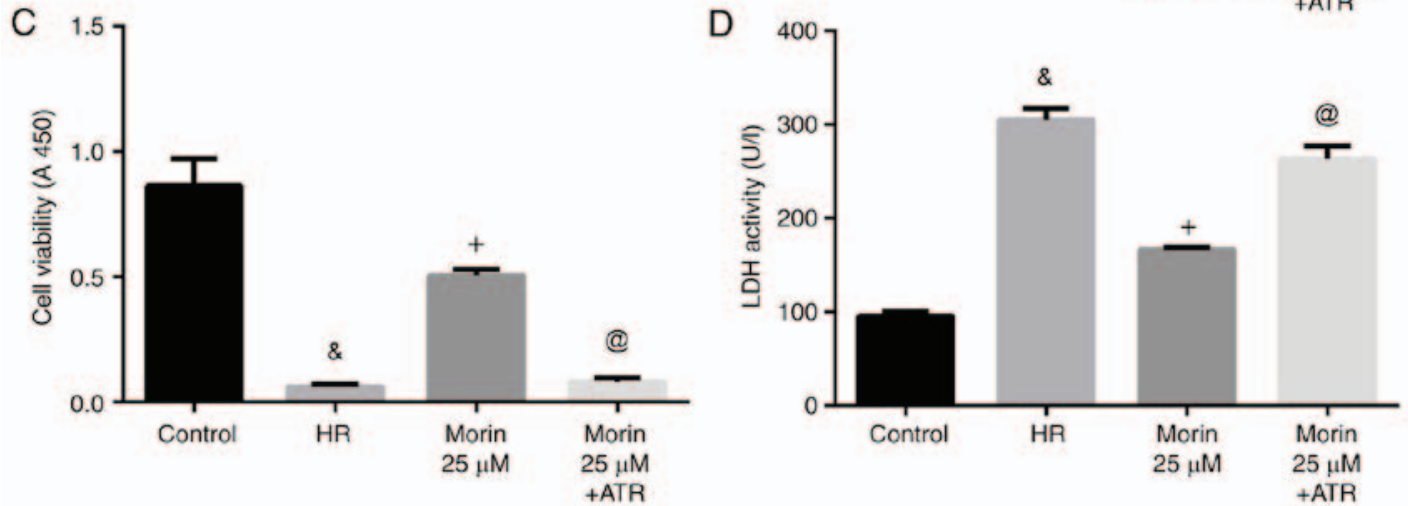

Figure 9. ATR abrogates the protective effects of morin. (A) Photomicrographs were captured at magnification, x400. (B) Results of myocardial 2, 3 , 5 -triphenyltetrazolium chloride staining and the percentage infarct size. The non-infarction areas were stained red or pink, whereas the infarction areas were white or gray. (C) Cell viability. (D) Cell LDH activity. Values are presented as the mean \pm standard deviation; $n=3-6$; ${ }^{*} \mathrm{P}<0.01$ vs. the IR group; ${ }^{\text {"}} \mathrm{P}<0.01$ vs. the morin 20 group; ${ }^{\&} \mathrm{P}<0.01$ vs. the control group; ${ }^{+} \mathrm{P}<0.01$ vs. the HR group; ${ }^{\circledR} \mathrm{P}<0.01$ vs. the morin 25 group. IR, ischemia-reperfusion; HR, hypoxia/reoxygenation; ATR, atractyloside.

MPTP opening may be regulated by Bax and Bcl-2 (40). The pro-apoptotic protein Bax may mediate MPTP opening through binding of adenine nucleotide translocase (ANT) or voltage-dependent anion channel (VDAC), while the anti-apoptotic protein Bcl-2 may directly inhibit the interaction between Bax and ANT/VDAC to inhibit MPTP opening by competing with ANT for the Bax binding site (41). The Bax/Bcl-2 balance is critical for maintaining cell homeostasis (42). Overexpression of Bcl-2 inhibits mitochondrial ROS production and the release of cytochrome $c$, and apoptosis-inducing factor. It may also increase mitochondrial calcium tolerance load, prevent caspase cascade activation and exert anti-apoptotic effects $(43,44)$. In the present study, the results demonstrated that morin treatment may significantly downregulate the expression of Bax, upregulate the expression of $\mathrm{Bcl}-2$ and decrease the ratio of Bax to Bcl-2. In addition, the Bax and $\mathrm{Bcl}-2$ expression levels following ATR rescue were also examined, but the results indicated that ATR did not affect the expressions of Bax and $\mathrm{Bcl}-2$ (data not shown). The primary explanation may be that ATR is an inducer of MPTP opening through the inhibition of adenine nucleotide translocator $(45,46)$. It may induce MPTP opening and activate mitochondrial downstream apoptotic pathway proteins, but cannot affect the expressions of Bax and Bcl-2. Therefore, we hypothesized that morin may regulate the MPTP opening by controlling the expression of Bax and Bcl-2.

Due to the absence of neural and humoral regulation in the isolated rat heart models of the present study, the pathophysiological changes normally observed during MIRI were not able to be simulated completely, which is a limitation of the present study. Therefore, the protective effect of morin on MIRI requires additional verification in vivo.

In conclusion, to the best of our knowledge, this is the first study to demonstrate morin-mediated prevention of MIRI. The protective effect of morin on MIRI may be associated with inhibition of MPTP opening. Therefore, morin may be a promising compound for MIRI prevention in the future.

\section{Acknowledgements}

Not applicable.

\section{Funding}

The present study was supported by the National Natural Science Foundation of China (grant no. 81670320) and the 
Natural Science Foundation of Liaoning Province (grant no. 201602826).

\section{Availability of data and materials}

The datasets used and analyzed during the current study are available from the corresponding author on reasonable request.

\section{Authors' contributions}

DJ and NW conceived and designed the experiments. SL conducted the experiments. JM, ZH and XL participated in the completion of the experiments. SL, PJ and YG analyzed the data. SL wrote the paper. NW revised the manuscript. All the authors read and approved the final paper.

\section{Ethics approval and consent to participate}

The experimental protocol was approved by the Institutional Ethics Committee of China Medical University.

\section{Patient consent for publication}

Not applicable.

\section{Competing interests}

The authors declare that they have no competing interests.

\section{References}

1. Writing Group Members, Mozaffarian D, Benjamin EJ, Go AS, Arnett DK, Blaha MJ, Cushman M, Das SR, de Ferranti S, Després JP, Fullerton HJ, et al: Heart disease and stroke statistics-2016 update: A report from the American Heart Association. Circulation 133: e38-360, 2016.

2. Guo X, Li Z, Vittinghoff E, Sun Y and Pletcher MJ: Trends in rate of acute myocardial infarction among patients aged $<30$ years. Nat Rev Cardiol 15: 119, 2018.

3. Plakht Y, Gilutz H and Shiyovich A: Excess long-term mortality among hospital survivors of acute myocardial infarction. Soroka Acute Myocardial Infarction (SAMI) project. Public Health 143: 25-36, 2017.

4. Bainey KR and Armstrong PW: Clinical perspectives on reperfusion injury in acute myocardial infarction. Am Heart J 167 637-645, 2014.

5. Gerczuk PZ and Kloner RA: An update on cardioprotection: A review of the latest adjunctive therapies to limit myocardial infarction size in clinical trials. J Am Coll Cardiol 59: 969-978, 2012.

6. Neri M, Riezzo I, Pascale N, Pomara C and Turillazzi E: Ischemia/reperfusion injury following acute myocardial infarction: A critical issue for clinicians and forensic pathologists. Mediators Inflamm 2017: 7018393, 2017.

7. Hausenloy DJ and Yellon DM: Myocardial ischemia-reperfusion injury: A neglected therapeutic target. J Clin Invest 123: 92-100, 2013.

8. Murry CE, Jennings RB and Reimer KA: Preconditioning with ischemia: A delay of lethal cell injury in ischemic myocardium. Circulation 74: 1124-1136, 1986.

9. Zhao ZQ, Corvera JS, Halkos ME, Kerendi F, Wang NP Guyton RA and Vinten-Johansen J: Inhibition of myocardial injury by ischemic postconditioning during reperfusion: Comparison with ischemic preconditioning. Am J Physiol Heart Circ Physiol 285: H579-H588, 2003.

10. Donato M, Evelson P and Gelpi RJ: Protecting the heart from ischemia/reperfusion injury: An update on remote ischemic preconditioning and postconditioning. Curr Opin Cardiol 32: 784-790, 2017
11. Zou R, Shi W, Tao J, Li H, Lin X, Yang S and Hua P: SIRT5 and post-translational protein modifications: A potential therapeutic target for myocardial ischemia-reperfusion injury with regard to mitochondrial dynamics and oxidative metabolism. Eur J Pharmacol 818: 410-418, 2018.

12. Liu J, Wang $\mathrm{H}$ and Li J: Inflammation and inflammatory cells in myocardial infarction and reperfusion injury: A double-edged sword. Clin Med Insights Cardiol 10: 79-84, 2016.

13. Badalzadeh R, Mokhtari B and Yavari R: Contribution of apoptosis in myocardial reperfusion injury and loss of cardioprotection in diabetes mellitus. J Physiol Sci 65: 201-215, 2015.

14. Morciano G, Bonora M, Campo G, Aquila G, Rizzo P, Giorgi C, Wieckowski MR and Pinton P: Mechanistic role of mPTP in ischemia-reperfusion injury. Adv Exp Med Biol 982: 169-189, 2017.

15. Ong SB, Samangouei P, Kalkhoran SB and Hausenloy DJ: The mitochondrial permeability transition pore and its role in myocardial ischemia reperfusion injury. J Mol Cell Cardiol 78: 23-34, 2015.

16. Hurst S, Hoek J and Sheu SS: Mitochondrial $\mathrm{Ca}^{2+}$ and regulation of the permeability transition pore. J Bioenerg Biomembr 49: 27-47, 2017.

17. Kwong JQ and Molkentin JD: Physiological and pathological roles of the mitochondrial permeability transition pore in the heart. Cell Metab 21: 206-214, 2015.

18. Šileikyte J and Forte M: Shutting down the pore: The search for small molecule inhibitors of the mitochondrial permeability transition. Biochim Biophys Acta 1857: 1197-1202, 2016.

19. Lim WY, Messow CM and Berry C: Cyclosporin variably and inconsistently reduces infarct size in experimental models of reperfused myocardial infarction: A systematic review and meta-analysis. Br J Pharmacol 165: 2034-2043, 2012.

20. Piot C, Croisille P, Staat P, Thibault H, Rioufol G, Mewton N Elbelghiti R, Cung TT, Bonnefoy E, Angoulvant D, et al: Effect of cyclosporine on reperfusion injury in acute myocardial infarction. N Engl J Med 359: 473-481, 2008.

21. Rizvi F, Mathur A and Kakkar P: Morin mitigates acetaminophen-induced liver injury by potentiating Nrf2 regulated survival mechanism through molecular intervention in PHLPP2-Akt-Gsk3 $\beta$ axis. Apoptosis 20: 1296-1306, 2015.

22. Chen Y, Li Y, Xu H, Li G, Ma Y and Pang YJ: Morin mitigates oxidative stress, apoptosis and inflammation in cerebral ischemic rats. Afr J Tradit Complement Altern Med 14: 348-355, 2017.

23. Zhang R, Kang KA, Piao MJ, Maeng YH, Lee KH, Chang WY, You HJ, Kim JS, Kang SS and Hyun JW: Cellular protection of morin against the oxidative stress induced by hydrogen peroxide. Chem Biol Interact 177: 21-27, 2009.

24. Kastenmayer RJ, Moore RM, Bright AL, Torres-Cruz R and Elkins WR: Select agent and toxin regulations: Beyond the eighth edition of the Guide for the Care and Use of Laboratory Animals. J Am Assoc Lab Anim Sci 51: 333-338, 2012.

25. Wu N, Li W, Shu W and Jia D: Protective effect of picroside II on myocardial ischemia reperfusion injury in rats. Drug Des Devel Ther 8: 545-554, 2014.

26. Livak KJ and Schmittgen TD: Analysis of relative gene expression data using real-time quantitative PCR and the $2^{-\Delta \Delta C \mathrm{~T}}$ method. Methods 25: 402-408, 2001.

27. Strutyns'ka NA, Dorofeieva NO, Vavilova HL and Sahach VF: Hydrogen sulfide inhibits $\mathrm{Ca}^{2+}$-induced mitochondrial permeability transition pore opening in spontaneously hypertensive rats. Fiziol Zh 59: 3-10, 2013 (In Ukrainian).

28. Nazari A, Sadr SS, Faghihi M, Azizi Y, Hosseini MJ, Mobarra N, Tavakoli A and Imani A: Vasopressin attenuates ischemia-reperfusion injury via reduction of oxidative stress and inhibition of mitochondrial permeability transition pore opening in rat hearts. Eur J Pharmacol 760: 96-102, 2015.

29. Alizadeh AM, Faghihi M, Khori V, Sohanaki H, Pourkhalili K, Mohammadghasemi F and Mohsenikia M: Oxytocin protects cardiomyocytes from apoptosis induced by ischemia-reperfusion in rat heart: Role of mitochondrial ATP-dependent potassium channel and permeability transition pore. Peptides 36: 71-77, 2012.

30. Al-Numair KS, Chandramohan G, Alsaif MA, Veeramani C and El Newehy AS: Morin, a flavonoid, on lipid peroxidation and antioxidant status in experimental myocardial ischemic rats. Afr J Tradit Complement Altern Med 11: 14-20, 2014. 
31. Liu CW, Yang F, Cheng SZ, Liu Y, Wan LH and Cong HL: Rosuvastatin postconditioning protects isolated hearts against ischemia-reperfusion injury: The role of radical oxygen species, PI3K-Akt-GSK-3 $\beta$ pathway, and mitochondrial permeability transition pore. Cardiovasc Ther 35: 3-9, 2017.

32. Xie Y, He Y, Cai Z, Cai J, Xi M, Zhang Y and Xi J: Tauroursodeoxycholic acid inhibits endoplasmic reticulum stress, blocks mitochondrial permeability transition pore opening, and suppresses reperfusion injury through GSK-3 $\beta$ in cardiac H9c2 cells. Am J Transl Res 8: 4586-4597, 2016.

33. Wang Y, Yuan Y, Wang X, Wang Y, Cheng J, Tian L, Guo X, Qin D and Cao W: Tilianin post-conditioning attenuates myocardial ischemia/reperfusion injury via mitochondrial protection and inhibition of apoptosis. Med Sci Monit 23: 4490-4499, 2017.

34. Chanoit G, Zhou J, Lee S, McIntosh R, Shen X, Zvara DA and $\mathrm{Xu} \mathrm{Z}$ : Inhibition of phosphodiesterases leads to prevention of the mitochondrial permeability transition pore opening and reperfusion injury in cardiac H9c2 cells. Cardiovasc Drugs Ther 25: 299-306, 2011.

35. Woodman OL, Long R, Pons S, Eychenne N, Berdeaux A and Morin D: The cardioprotectant 3',4'-dihydroxyflavonol inhibits opening of the mitochondrial permeability transition pore after myocardial ischemia and reperfusion in rats. Pharmacol Res 81: 26-33, 2014.

36. Tsujimoto Y and Shimizu S: Role of the mitochondrial membrane permeability transition in cell death. Apoptosis 12: 835-840, 2007.

37. Hüttemann M, Helling S, Sanderson TH, Sinkler C, Samavati L, Mahapatra G, Varughese A, Lu G, Liu J, Ramzan R, et al: Regulation of mitochondrial respiration and apoptosis through cell signaling: Cytochrome $c$ oxidase and cytochrome $c$ in ischemia/reperfusion injury and inflammation. Biochim Biophys Acta 1817: 598-609, 2012.

38. Kim JS, He L and Lemasters JJ: Mitochondrial permeability transition: A common pathway to necrosis and apoptosis. Biochem Biophys Res Commun 304: 463-470, 2003.

39. Yang S, Li H, Tang L, Ge G, Ma J, Qiao Z, Liu H and Fang W: Apelin-13 protects the heart against ischemia-reperfusion injury through the RISK-GSK-3 $\beta$-mPTP pathway. Arch Med Sci 11: 1065-1073, 2015.
40. Chen Z, Chua CC, Ho YS, Hamdy RC and Chua BH: Overexpression of $\mathrm{Bcl} 2$ attenuates apoptosis and protects against myocardial I/R injury in transgenic mice. Am J Physiol Heart Circ Physiol 280: H2313-H2320, 2001.

41. Dejean LM, Martinez-Caballero S, Guo L, Hughes C, Teijido O, Ducret T, Ichas F, Korsmeyer SJ, Antonsson B, Jonas EA and Kinnally KW: Oligomeric Bax is a component of the putative cytochrome $c$ release channel MAC, mitochondrial apoptosis-induced channel. Mol Biol Cell 16: 2424-2432, 2005.

42. Dong JW, Zhu HF, Zhu WZ, Ding HL, Ma TM and Zhou ZN: Intermittent hypoxia attenuates ischemia/reperfusion induced apoptosis in cardiac myocytes via regulating $\mathrm{Bcl} 2 / \mathrm{Bax}$ expression. Cell Res 13: 385-391, 2003.

43. Imahashi K, Schneider MD, Steenbergen C and Murphy E: Transgenic expression of $\mathrm{Bcl} 2$ modulates energy metabolism, prevents cytosolic acidification during ischemia, and reduces ischemia/reperfusion injury. Circ Res 95: 734-741, 2004.

44. Hochhauser E, Kivity S, Offen D, Maulik N, Otani H, Barhum Y, Pannet H, Shneyvays V, Shainberg A, Goldshtaub V, et al: Bax ablation protects against myocardial ischemia-reperfusion injury in transgenic mice. Am J Physiol Heart Circ Physiol 284: H2351-H2359, 2003

45. Halestrap AP, Clarke SJ and Javadov SA: Mitochondrial permeability transition pore opening during myocardial reperfusion-a target for cardioprotection. Cardiovasc Res 61: $372-385,2004$

46. Javadov S, Karmazyn M and Escobales N: Mitochondrial permeability transition pore opening as a promising therapeutic target in cardiac diseases. J Pharmacol Exp Ther 330: 670-678, 2009.

This work is licensed under a Creative Commons Attribution-NonCommercial-NoDerivatives 4.0 International (CC BY-NC-ND 4.0) License. 